\title{
ENHANCEMENT OF SOLUBILITY AND DISSOLUTION RATE OF DOMPERIDONE BY UTILIZING DIFFERENT TECHNIQUES
}

\author{
E. H. Ibrahim, T. H. El-Faham, F.A. Mohammed and N. S. El-Eraky \\ Department of Pharmaceutics, Faculty of Pharmacy, Assiut University, Assiut, P.O 71526, \\ Egypt
}

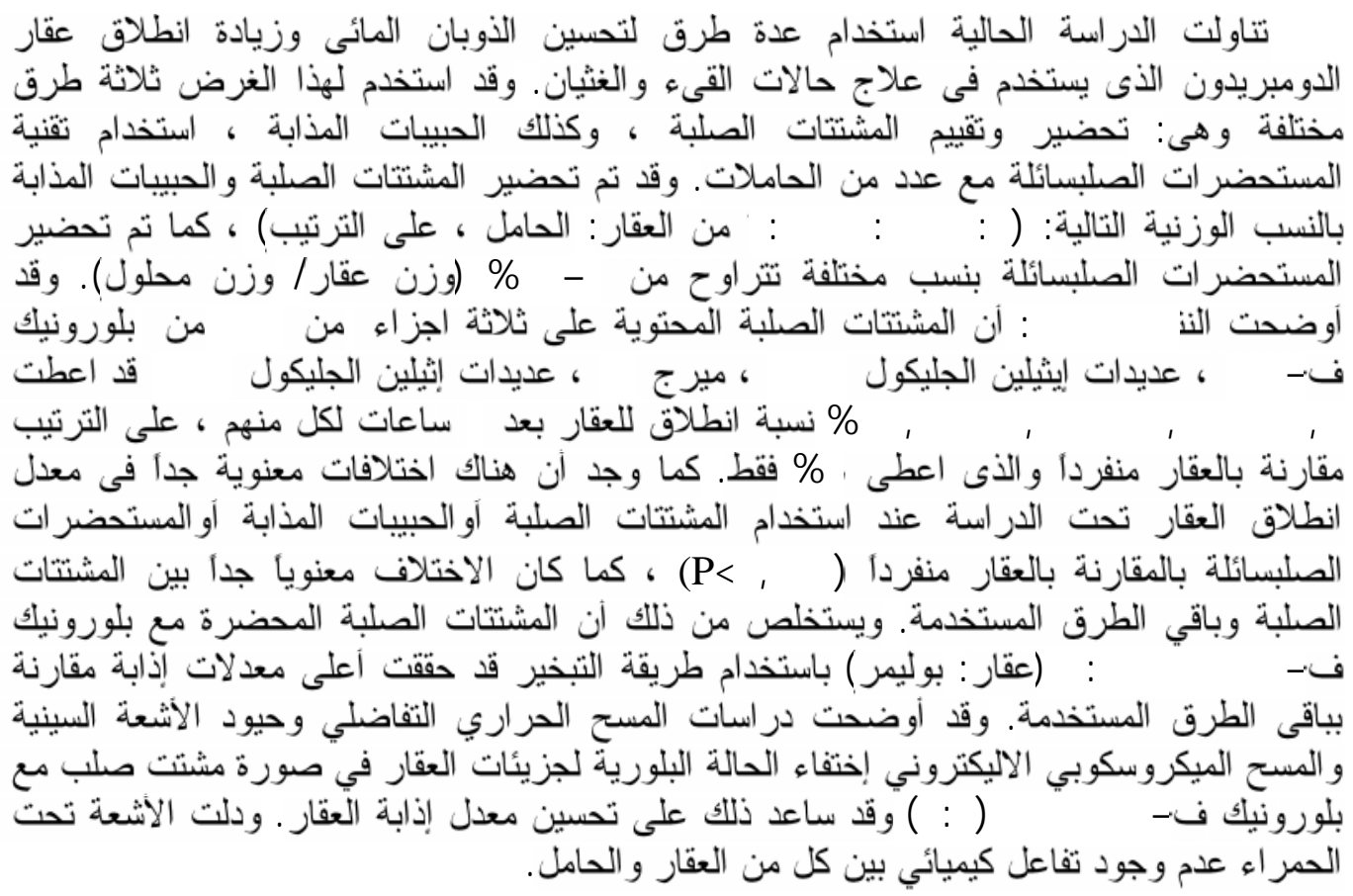

The aim of this study was to enhance solubility and dissolution of water insoluble antiemetic drug, domperidone, with three different techniques viz., solid dispersion, melt granulation, and liquisolid compacts techniques. Solid dispersion and melt granulation systems at 1:1, 1:2 and 1:3 drug to polymer ratios were prepared. Several liquisolid formulations containing various ratios of drug: liquid vehicle (ranging from $5 \%$ to $50 \% \mathrm{w} / \mathrm{w}$ ) were formulated. The IR spectroscopy, scanning electron microscopy (SEM), X-ray powder diffractometry (XRD) and differential scanning calorimetry (DSC) were used to examine the physical state of the drug. Furthermore, the solubility and the in-vitro dissolution of the drug from the different systems were studied. The in-vitro dissolution study showed that the percent of the drug dissolved from solid dispersions containing 3 parts of each of PF-127, PEG 6000, Myrj 52 or PEG 4000 is 54.3, 48.98, 43.37, and 43.2\% after 6 hrs respectively, compared to only $8 \%$ dissolved of drug alone. There is a highly significant difference in \% of domperidone dissolved from solid dispersion, melt granulation, and liquisolid compacts systems compared to drug alone $(P<0.001)$, also the difference between solid dispersion system compared to the other systems was highly significant $(P<0.001)$. It can be concluded that domperidone aqueous solubility and dissolution were markedly improved via solid dispersion technique with PF-127 prepared by solvent evaporation method compared to other methods used. The data from the (SEM), (XRD) and (DSC) revealed absence of crystalline structure for domperidone in its solid dispersion with Pluronic F-127 (1:3) drug to polymer ratio. Also, the IR spectra indicated the absence of well defined interaction. 


\section{INTRODUCTION}

Domperidone, (Domperidonum), 5Chloro-1-[1-[3-(2,3-dihydro-2-oxo-1H-benzimidazol-1-yl)propyl]-4-piperidinyl]-1,3-dihydro-2H-benzimidazol-2- one, with a molecular formula of $\mathrm{C}_{22} \mathrm{H}_{24} \mathrm{ClN}_{5} \mathrm{O}_{2}{ }^{1}$. It is a dopamine (D2) receptor antagonist. Domperidone has been used for the treatment and prevention of acute nausea and vomiting in adults from any cause specifically; cytotoxic therapy and radiotherapy, nausea and vomiting associated with 1-dopa and bromocriptine treatment for parkinsonian patients. It is also used in case of stimulation of gut mobility as in non-ulcer dyspepsia, esophageal reflux and gastritis $^{1 \& 2}$. Systemic bioavailability following oral administration is about $13-17 \%$ because of extensive presystemic metabolism (83-87\%) in the gut wall and liver. Furthermore; domperidone is practically insoluble in water and the solubility characteristics of a drug greatly influence its ability to penetrate the biological membranes ${ }^{3 \& 4}$.

Potential bioavailability problems are prevalent with extremely hydrophobic drugs due to erratic or incomplete absorption from gastrointestinal tract $(\mathrm{GIT})^{5 \& 6}$. Solid dispersions are one of the most promising strategies to improve the dissolution properties and hence bioavailability of slightly watersoluble drug compounds. The drug can be dissolved in a matrix or it can be homogeneously dispersed as fine particles in amorphous or crystalline carriers. The solid dispersion technology provides the possibility to reduce the drug particle size to a molecular level and increased wettablility. In addition, a transformation of the drug from the crystalline to the amorphous state can occur, which can be beneficial since dissolution of an amorphous drug does not require energy to break up the crystalline lattice ${ }^{7-16}$.

A melt granulation technique is a process by which pharmaceutical powders can be efficiently agglomerated by the use of a molten binder at relatively low temperature (50$\left.80^{\circ} \mathrm{C}\right)^{17}$. This process can be used for the preparation of sustained released dosage forms by using lipophilic binders, or fast release formulations by utilizing water-soluble binders, such as PEG. The interest in melt granulation has increased due to the advantage of this technique, that is, it negates any risk originating from residual solvents; moreover, in melt granulation the drying step is not necessary, thus the process is less consuming in terms of time and energy ${ }^{18 \& 19}$.

"Liquisolid compacts" is a new and promising technique; they are acceptably flowing and compressible powdered forms of liquid medications. The term 'liquid medication' implies oily liquid drugs and solutions or suspensions of water insoluble solid drugs carried in suitable nonvolatile solvent systems termed the liquid vehicles. Using this new formulation technique, a liquid medication may be converted into a drylooking, non-adherent, free flowing and readily compressible powder by a simple blending with selected powder excipients referred to as the carrier and coating materials. Various grades of cellulose, starch, lactose, etc., may be used as the carriers, whereas very fine particle size silica powders may be used as the coating (or covering) materials. Due to significantly increased wetting properties and surface area of drug available for dissolution, and also due to the drug is held within the powder substrate in solution or, in a solubilized, almost molecularly dispersed state, liquisolid compacts of waterinsoluble substances may be expected to display enhanced drug release characteristics and, consequently, improved bioavailability ${ }^{20-23}$.

The objective of this work was to evaluate the feasibility of the solid dispersion, melt granulation and liquisolid compact techniques to improve the dissolution characteristics of a poorly water-soluble drug, domperidone.

\section{MATERIALS AND METHODS}

\section{Materials}

Domperidone (Pharco, for Pharmaceutical and Chemical Industry, Cairo, Egypt), Polyethylene glycol 200, and 400 (Morgan Chemical IND.Co., Cairo, Egypt). Propylene glycol (PG) (Evans Chem.CO., Cairo, Egypt), Polyvinyl pyrrolidone 40000, Polyethylene glycol 4000, and 6000, Myrj 52, Pluronic F127 (PF-127) and Pluronic F-68 (PF-68) (Sigma - Aldrich Co, St. Louis Missouri, USA), Brij 35 (Merck Schuchardt OHG, Hohenbrunn, Germany), Mannitol BP80 was packed and distributed by (El-Gomhouria Co, Cairo, Egypt), Avicel $^{\circledR}$ PH-102 grade (C.P. 
Evans Co, Cairo, Egypt), Aerosil ${ }^{\circledR} 200$ (ADWIC- El-Nasr Co., Cairo, Egypt), Polysorbate 20, 40, 60 and 80, Urea, Potassium dihydrogen orthophosphate, Sodium hydroxide, Methyl alcohol and Dimethyl formamide (ElNasr Pharmaceutical Chemicals, Cairo, Egypt). All chemicals used were of pharmaceutical grade and were used as received.

\section{Methods}

\section{Preparation of physical mixture}

Initially domperidone and solid carriers were sieved through $212 \mu \mathrm{m}$ sieve, and then the physical mixtures in the determined ratios were prepared by simple gentle mixing using spatula and paper method.

\section{Preparation of solid dispersions by co- evaporation method}

Solid dispersions of domperidone with PEG 6000, PEG 4000, Myrj 52, and Pluronic F-127 at weight ratio of $(1: 1,1: 2$, and $1: 3)$, drug to carrier were prepared. The solvent evaporation method was applied. Solution of the drug and the investigated carriers, in the calculated ratios, were prepared and the solvent was removed by evaporation at room temperature on magnetic stirrer. The coprecipitates were then scrapped and dried in a hot air oven at $40^{\circ} \mathrm{C}$ for $24 \mathrm{hrs}$, pulverized by mortar and pestle, then sieved and the particle size range of $150-212 \mu \mathrm{m}$ was collected. A specified sample of the prepared solid dispersion was assayed for the drug content.

\section{Preparation of granulates}

Granules were prepared employing various water-soluble carriers viz. poloxamers (PF-68, and PF-127), polyols (mannitol), hydrotropes (urea), Brij 35, Myrj 52, PEGs (4000, and 6000) in $(1: 1,1: 2,1: 3)$ drug to carrier ratios by hot-melt method. Each carrier was melted over a thermostatically controlled magnetic stirrer at its respective melting point and drug was incorporated into the molten carrier mass. The blend was heated at the corresponding temperature for $5 \mathrm{~min}$, followed by flash-cooling on an ice bath. Then it was stored in a desiccator for $24 \mathrm{~h}$. Subsequently, ground in a mortar and passed through $212 \mu \mathrm{m}$ sieve.

\section{Preparation of domperidone liquisolid compacts}

Several liquisolid systems of domperidone (denoted as LS-1-LS-27) were prepared. All liquisolid formulations contained (Avicel ${ }^{\circledR} \mathrm{PH}-$ $102)$ as the carrier powder and (Aerosil $\left.{ }^{\circledR} 200\right)$ as the coating (covering) material at a fixed powder excipient ratio (R) of 20. Also, different liquid vehicles were employed as shown in table 1. Depending on the liquid vehicle and drug concentration in the liquid medication used, different reported liquid load factors (Lf) ranging from 0.195 to $0.235(\mathrm{w} / \mathrm{w})$ were employed in our liquisolid preparations ${ }^{20-}$ ${ }^{23}$. In order to prepare the liquisolid system, the appropriate amount of carrier Avicel ${ }^{\circledR} \mathrm{PH}-102$ was mixed with the drug-vehicle suspension. $\left(\right.$ Aerosil ${ }^{\circledR} 200$ ) was then added to convert the wet mixture into dry powder under continuous mixing.

\section{Infra-red spectroscopy studies}

Studies of the IR spectra of the drug alone, polymers used, the physical mixture, and the formula (solid dispersions, granules, or liquisolid compacts) of the selected ratios were conducted using a Shimadzu spectrophotometer (model 470, Japan) and the $\mathrm{KBr}$ disk method.

\section{Differential scanning calorimetry}

The DSC thermograms were obtained using differential scanning calorimeter (DSC, model 50, Shimadzu, Japan). Samples (5 mg) were weighed in aluminum pans and heated at a scanning rate of $10^{\circ} \mathrm{C} / \mathrm{min}$ from 30 to $350^{\circ} \mathrm{C}$ in the presence of nitrogen at flow rate of 40 $\mathrm{ml} / \mathrm{min}$.

\section{Powder X-ray diffraction}

XRD was performed on domperidone, Pluronic F-127, physical mixture, and solid dispersion with Pluronic F-127 at (1:3) drug to carrier ratio. Each powder sample was carried out with Philips (PW-1050, Bragg-Brentano) diffractometer; $\mathrm{Cu} \mathrm{K} \alpha$ radiation $(35 \mathrm{Kv}, 40$ $\mathrm{mA}$, slit $1.5418 \mathrm{~A}^{\circ}$ ).

\section{Scanning electron microscopy (SEM)}

SEM was performed on domperidone, Pluronic F-127, physical mixture, and solid dispersion with Pluronic F-127 at (1:3) drug to carrier ratio using a JSM-6400 (Joel, Japan) by coating the samples with gold using ion sputtering at $15 \mathrm{Kv}$. Digital images of the samples were obtained. 
Table 1: Key formulation characteristics of prepared domperidone liquisolid compacts.

\begin{tabular}{|c|c|c|c|c|c|}
\hline $\begin{array}{c}\text { Liquisolid } \\
\text { system }\end{array}$ & $\begin{array}{c}\text { Liquid } \\
\text { vehicle }\end{array}$ & $\begin{array}{c}\text { Drug } \\
\text { concentration } \\
\text { in liquid } \\
\text { medication } \\
(\% \text { w/w })\end{array}$ & $\begin{array}{c}\text { Liquid } \\
\text { load } \\
\text { factor( }\end{array}$ & $\begin{array}{c}\text { Carrier : Coating } \\
(\mathrm{R})\end{array}$ & $\begin{array}{c}\text { Unit dose weight } \\
(\mathrm{mg})\end{array}$ \\
\hline LS-1 & Tween 80 & 5 & 0.195 & 20 & 638.46 \\
\hline LS-2 & Tween 80 & 10 & 0.200 & 20 & 625 \\
\hline LS-3 & Tween 80 & 12.5 & 0.203 & 20 & 617.24 \\
\hline LS-4 & Tween 80 & 15 & 0.205 & 20 & 612.19 \\
\hline LS-5 & Tween 80 & 17.5 & 0.207 & 20 & 607.24 \\
\hline LS-6 & Tween 80 & 20 & 0.210 & 20 & 599.99 \\
\hline LS-7 & Tween 80 & 25 & 0.215 & 20 & 588.37 \\
\hline LS-8 & Tween 80 & 30 & 0.220 & 20 & 577.27 \\
\hline LS-9 & Tween 80 & 40 & 0.225 & 20 & 566.66 \\
\hline LS-10 & Tween 80 & 50 & 0.225 & 20 & 566.66 \\
\hline LS-11 & Tween 60 & 5 & 0.195 & 20 & 638.46 \\
\hline LS-12 & Tween 60 & 10 & 0.200 & 20 & 625 \\
\hline LS-13 & Tween 40 & 5 & 0.195 & 20 & 638.46 \\
\hline LS-14 & Tween 40 & 10 & 0.200 & 20 & 625 \\
\hline LS-15 & Tween 20 & 5 & 0.195 & 20 & 638.46 \\
\hline LS-16 & Tween 20 & 10 & 0.200 & 20 & 625 \\
\hline LS-17 & PEG 200 & 5 & 0.195 & 20 & 638.46 \\
\hline LS-18 & PEG 200 & 10 & 0.200 & 20 & 625 \\
\hline LS-19 & PEG 200 & 12.5 & 0.203 & 20 & 617.24 \\
\hline LS-20 & PEG 200 & 15 & 0.205 & 20 & 612.19 \\
\hline LS-21 & PEG400 & 5 & 0.168 & 20 & 724.99 \\
\hline LS-22 & PEG400 & 20 & 0.168 & 20 & 724.99 \\
\hline LS-23 & PEG400 & 40 & 0.168 & 20 & 724.99 \\
\hline LS-24 & PG & 5 & 0.225 & 20 & 566.66 \\
\hline LS-25 & PG & 10 & 0.230 & 20 & 556.52 \\
\hline LS-26 & PG & 12.5 & 0.232 & 20 & 552.58 \\
\hline LS-27 & PG & 15 & 0.235 & 20 & 546.80 \\
\hline \hline & & & & & \\
\hline
\end{tabular}

\section{Solubility determination}

The Solubility of domperidone was carried out by adding an amount of the prepared formulas equivalent to $5 \mathrm{mg}$ of the drug to $10 \mathrm{ml}$ of distilled water in conical flask covered with foil and shaked at $37^{\circ} \mathrm{C}$ for $2 \mathrm{hrs}$. The samples were filtered, properly diluted and analyzed spectrophotometrically at $284 \mathrm{~nm}^{24}$ to measure the amount of dissolved domperidone. All experiments were conducted in triplicate and the results presented are the mean values of the three experiments.

\section{Dissolution studies}

The dissolution of domperidone from the selected formulas and the corresponding physical mixtures as well as the drug alone was studied using the U.S.P 25 dissolution apparatus II (paddle type). Accurately weighed amounts equivalent to $10 \mathrm{mg}$ of domperidone were dispersed in $500 \mathrm{ml}$ of the dissolution medium (phosphate buffer $\mathrm{pH} 7.4$ ) at $37 \pm 0.5^{\circ} \mathrm{C}$ stirred at $100 \mathrm{rpm}$. At appropriate time intervals, samples $(5 \mathrm{ml})$ were withdrawn over a period of six hours and replaced by an equal volume of fresh buffer. The samples were filtered and the drug content was determined spectrophotometrically at $284 \mathrm{~nm}^{24}$, all experiments were carried out in triplicate and the results presented are the mean values of the three experiments; the error bars represent the S.D.

\section{Statistical analysis}

The results of the dissolution study were evaluated and analyzed statistically with the Prism ver. 5. (Graph Pad Software, USA) computer program. For statistical evaluations, 
data were analyzed by two-way analysis of variance (ANOVA) using Bonferroni test. Differences between means were considered statistically non-significant (NS) if the $\mathrm{P}$ value was >0.05. When $0.05>\mathrm{P} \geq 0.01$ the parameters taken as significantly (S) different and when $0.01>\mathrm{P} \geq 0.001$ they were regarded to be highly significant (HS) different.

\section{RESULTS AND DISCUSSION}

\section{Spectroscopic studies}

The spectroscopic survey done in this work was to reveal any changes in the absorption maximum and thermal behavior of domperidone as a result of its admixture with polymers in different prepared systems.

\section{Infra-red spectral studies}

Figures 1-4 show the characteristic IR bands of domperidone in different prepared systems; solid dispersions, melt granulations, and liquisolid compacts. For solid dispersion systems; Figure 1, Trace (a), refers to the IR spectrum of domperidone, the characteristic bands are at $3300-3400 \mathrm{~cm}^{-1}$, denoting $\mathrm{N}-\mathrm{H}$ stretching; $1600 \mathrm{~cm}^{-1}$ representing $\mathrm{C}=\mathrm{O}$ stretching, $3100 \mathrm{~cm}^{-1}$ indicating $\mathrm{SP}^{2} \mathrm{C}-\mathrm{H}$ stretching, 2800-2900 $\mathrm{cm}^{-1}$ denoting $\mathrm{SP}^{3} \mathrm{C}-\mathrm{H}$ stretching and several bands at $1400-1600 \mathrm{~cm}^{-1}$ representing aromatic $\mathrm{C}=\mathrm{C}$.

The IR spectra of physical mixtures; Figure 1, Trace (c, f, i and l) and solid dispersions, Trace $(\mathrm{g}, \mathrm{j}$, and $\mathrm{m}$ ), is a superposition of drug and polymer spectra. These results indicate the absence of well defined interaction between domperidone and the used polymers.

For melt granulation systems; Figures 2 and 3; Figure 3, Trace (q) shows the characteristic bands of mannitol, it was seen that the O-H signal of mannitol formed a broad band around $3270 \mathrm{~cm}^{-1}$. In the melt granulation, peak of asymmetric $\mathrm{C}-\mathrm{H}$ vibrational stretching of mannitol between 2880 and $3000 \mathrm{~cm}^{-1}$ distinctively changes. This indicates that mannitol in the original form, as well as in the physical mixtures, existed in the thermodynamically stable modification (modification I) ${ }^{25}$. The melt granulation preparation caused the formation of thermodynamically less stable modification II, which is monotropically related to modification
I. From these results, it was concluded that there were no intermolecular interactions between the drug and the carrier.

Figures 2 and 3 indicated that there was no physicochemical interaction between domperidone and the carriers used in the prepared physical mixtures or melt granulation systems.

For liquisolid compacts systems; Figure 4, Trace (b), belongs to Avicel ${ }^{\circledR} \mathrm{PH}-102$ showed major peak at $3409 \mathrm{~cm}^{-1}(\mathrm{O}-\mathrm{H}$ stretching) and Trace (c) Aerosil ${ }^{\circledR} 200$ at $3409 \mathrm{~cm}^{-1}(\mathrm{O}-\mathrm{H}$ stretching). IR spectra of physical mixture and liquisolid compact revealed absence of any well defined interaction between the drugs and the carriers used.
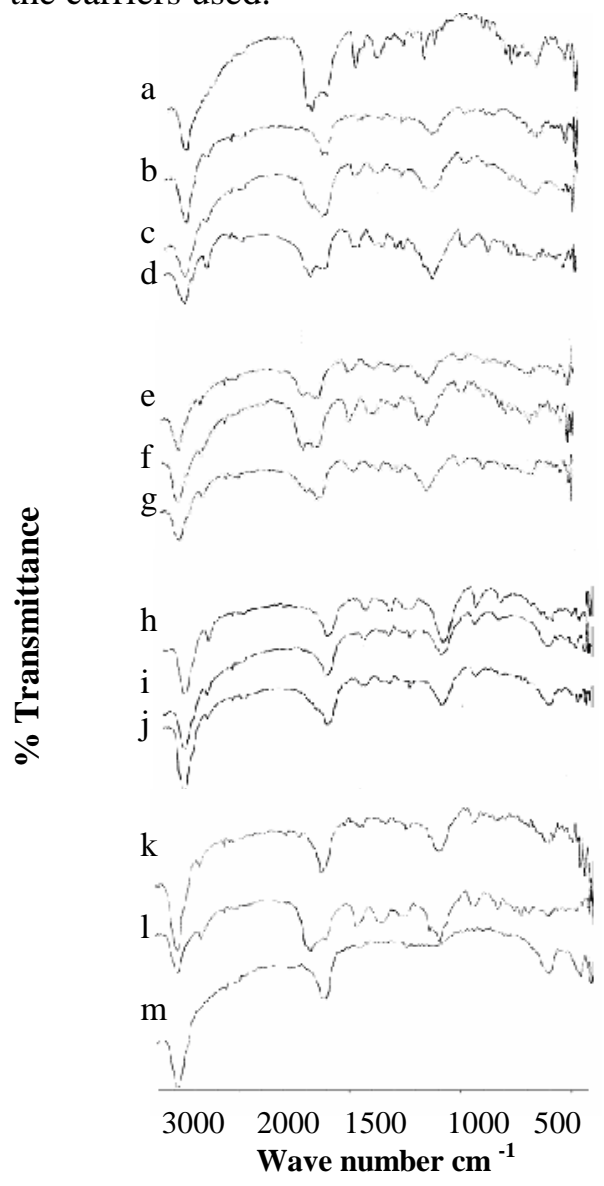

Fig. 1: IR spectra of pure materials, solid dispersions, and corresponding physical mixtures. (a) domperidone, (b) Pluronic F-127, (c) physical mixture of domperidone / Pluronic F-127, (d) solid dispersion of domperidone / Pluronic F127, (e) Myrj 52, (f) physical mixture of domperidone / Myrj 52, (g) solid dispersion of domperidone / Myrj 52, (h) PEG 4000, (i) physical mixture of domperidone / PEG 4000, (j) solid dispersion of domperidone / PEG 4000, (k) PEG 6000, (l) physical mixture of domperidone / PEG 6000, (m) solid dispersion of domperidone / PEG 6000. 


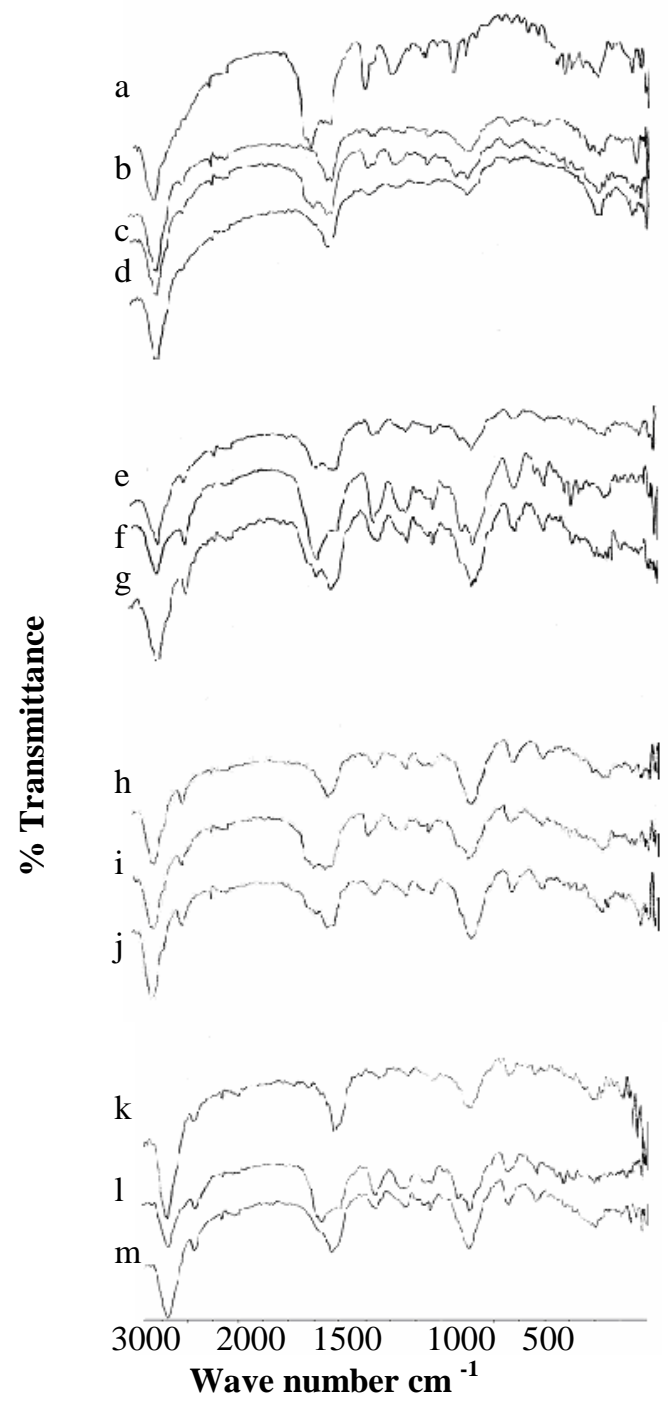

Fig. 2: IR spectra of pure materials, melt granulations, and corresponding physical mixtures. (a) domperidone, (b) Pluronic F127, (c) physical mixture of domperidone / Pluronic F-127, (d) melt granulations of domperidone / Pluronic F-127, (e) Myrj 52, (f) physical mixture of domperidone / Myrj 52 , (g) melt granulations of domperidone / Myrj 52, (h) PEG 4000, (i) physical mixture of domperidone / PEG 4000, (j) melt granulations of domperidone / PEG 4000, (k) PEG 6000, (l) physical mixture of domperidone / PEG 6000, (m) melt granulations of domperidone / PEG 6000.
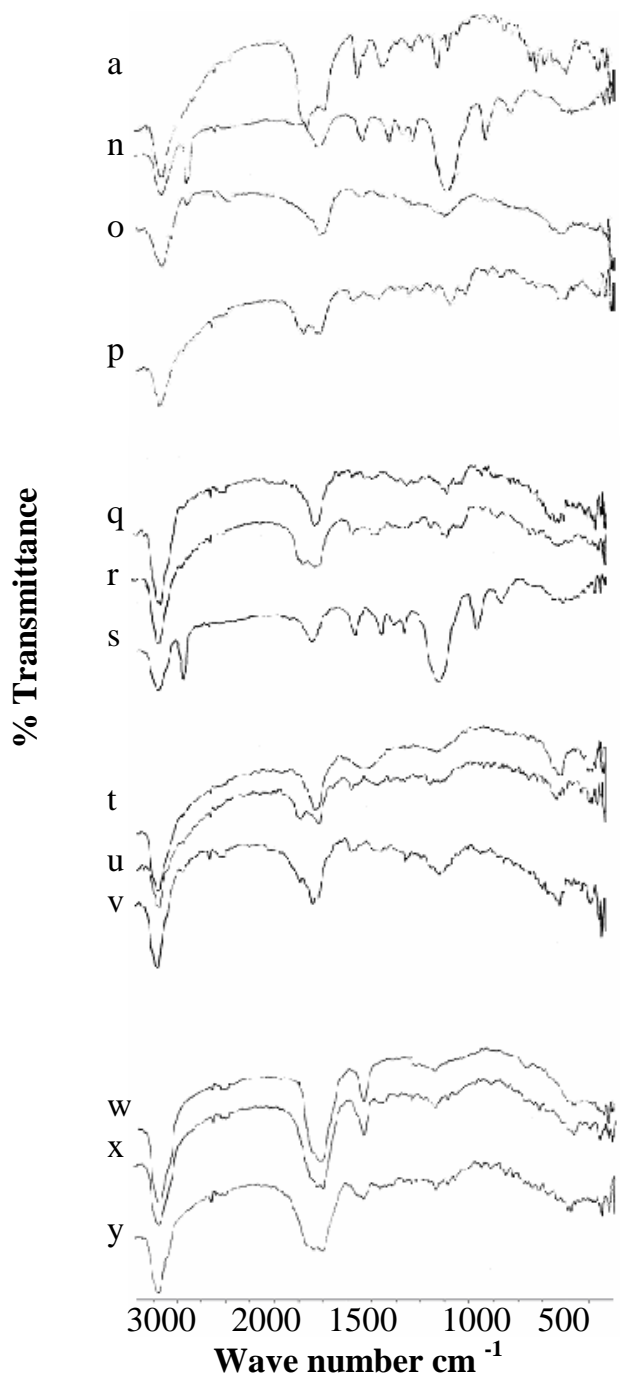

Fig. 3: IR spectra of pure materials, melt granulations, and corresponding physical mixtures. (a) domperidone, (n) Brij 35, (o) physical mixture of domperidone / Brij 35, (p) melt granulations of domperidone / Brij 35, (q) Mannitol, (r) physical mixture of domperidone / Mannitol, (s) melt granulations of domperidone / Mannitol, (t) Pluronic F-68, (u) physical mixture of domperidone / Pluronic F-68, (v) melt granulations of domperidone / Pluronic F68, (w) Urea, (x) physical mixture of domperidone / Urea, (y) melt granulations of domperidone / Urea. 


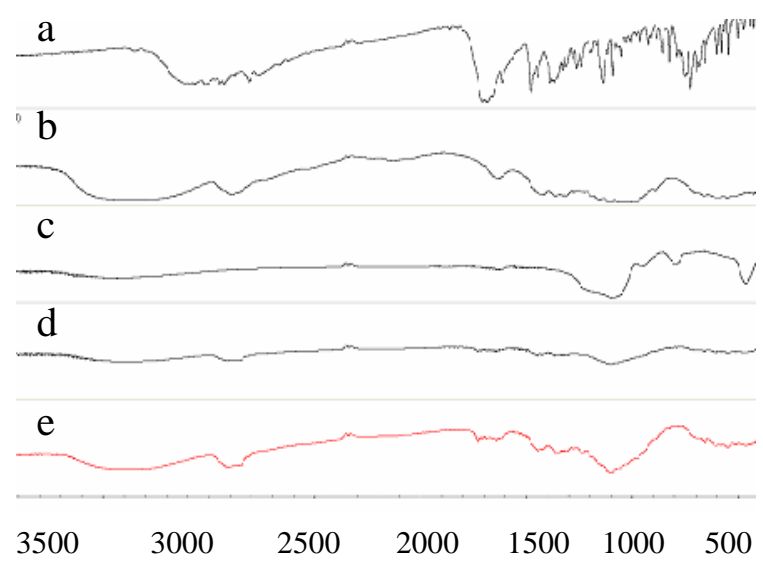

Wave number $\mathrm{cm}^{-1}$

Fig. 4: Infra-red spectra of domperidone / liquisolid compact system. (a) Drug alone; (b) Avicel; (c) Aerosil, and (d) Physical mixture; (e) liquisolid compacts (10\% tween 80 ).

\section{Differential scanning calorimetry (DSC)}

Figures 5-8 show the DSC thermogram curves of domperidone - carrier systems. The melting endotherm of domperidone alone was observed at $248.09^{\circ} \mathrm{C}$ with onset $242.05^{\circ} \mathrm{C}$ and $\mathrm{H}$ of -79.54 joule/g, while in solid dispersions, melt granulations and in physical mixtures the melting endotherm of drug was observed as a broad endotherm at a temperature range lower than the melting point of the drug. Also the characteristic feature of domperidone peak, e.g. sharpness was lost. These results may be attributed to the reduction in crystallinity of domperidone in the prepared systems.

These findings may not be indicative of the physical state of domperidone within the dispersion. Since the most used polymers melted before the drug, there is a possibility that the crystalline domperidone might dissolve in the molten carrier during the DSC scan and converted to the amorphous form.
This is similar to the melt method used to prepare solid dispersions. The broadness and shift of melting endotherm, therefore, may be due to the formation of amorphous domperidone during the DSC scan and not necessarily due to its presence in the solid dispersion. This is further substantiated by the broadness and shift of a melting endotherm in the physical mixture.

For liquisolid compacts systems; Figure 8, the thermograms of Avicel PH 102 Trace (b), displayed two broad endothermic peaks at 84.23 and $328.54^{\circ} \mathrm{C}$ that might correspond to the volatilization of adsorbed water followed by melting decomposition with charring of the crystalline cellulosic material. Trace (c), represents the thermal behavior for pure Aerosil ${ }^{\circledR} 200$, it did not show any sharp peaks; proving that the coating material was almost in an amorphous state. On the other hand, the liquisolid system thermogram Trace (d) displayed complete disappearance of the characteristic peak of domperidone; a fact that agrees with the formation of drug solution in the liquisolid powdered system, i.e., the drug was molecularly dispersed within the liquisolid matrix. Such disappearance of the drug peaks upon formulation of the liquisolid system was in agreement with Mccauley and Brittain ${ }^{26}$ who declared that the complete suppression of all drug thermal features, undoubtedly indicate the formation of an amorphous solid solution. Additionally, Mura et al. ${ }^{27}$ found out that the total disappearance of the drug melting peak indicates that drug amorphization was obtained. It has been known that transforming the physical state of the drug to amorphous or partially amorphous state leads to a high energy state and high disorder, resulting in enhanced solubility and faster dissolution. 


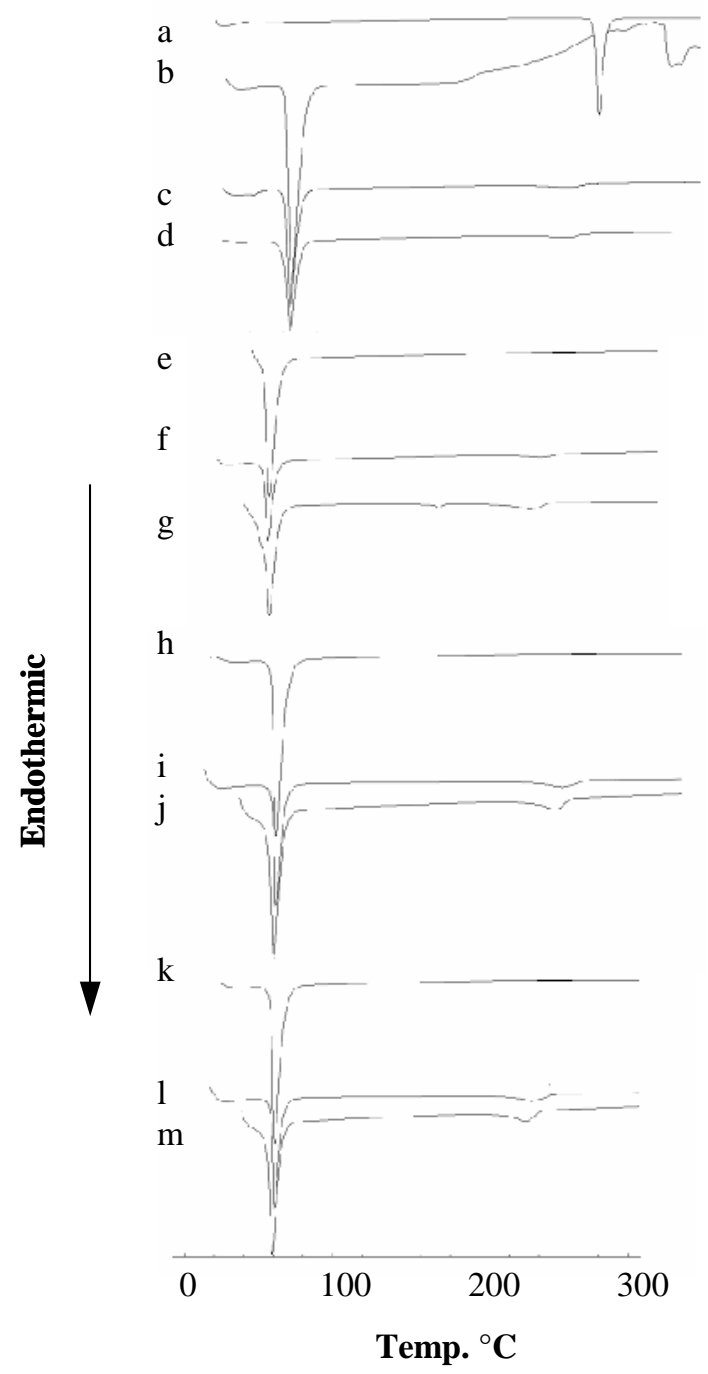

Fig. 5: DSC curves of single components and binary systems of domperidone and Pluronic F-127, Myrj 52, PEG 4000 and PEG 6000. (a) domperidone, (b) Pluronic F-127, (c) physical mixture of domperidone / Pluronic F-127, (d) solid dispersion of domperidone / Pluronic F-127, (e) Myrj 52, (f) physical mixture of domperidone / Myrj 52, (g) solid dispersion of domperidone / Myrj 52, (h) PEG 4000, (i) physical mixture of domperidone / PEG 4000, (j) solid dispersion of domperidone / PEG 4000, (k) PEG 6000, (l) physical mixture of domperidone / PEG 6000, (m) solid dispersion of domperidone / PEG 6000 .

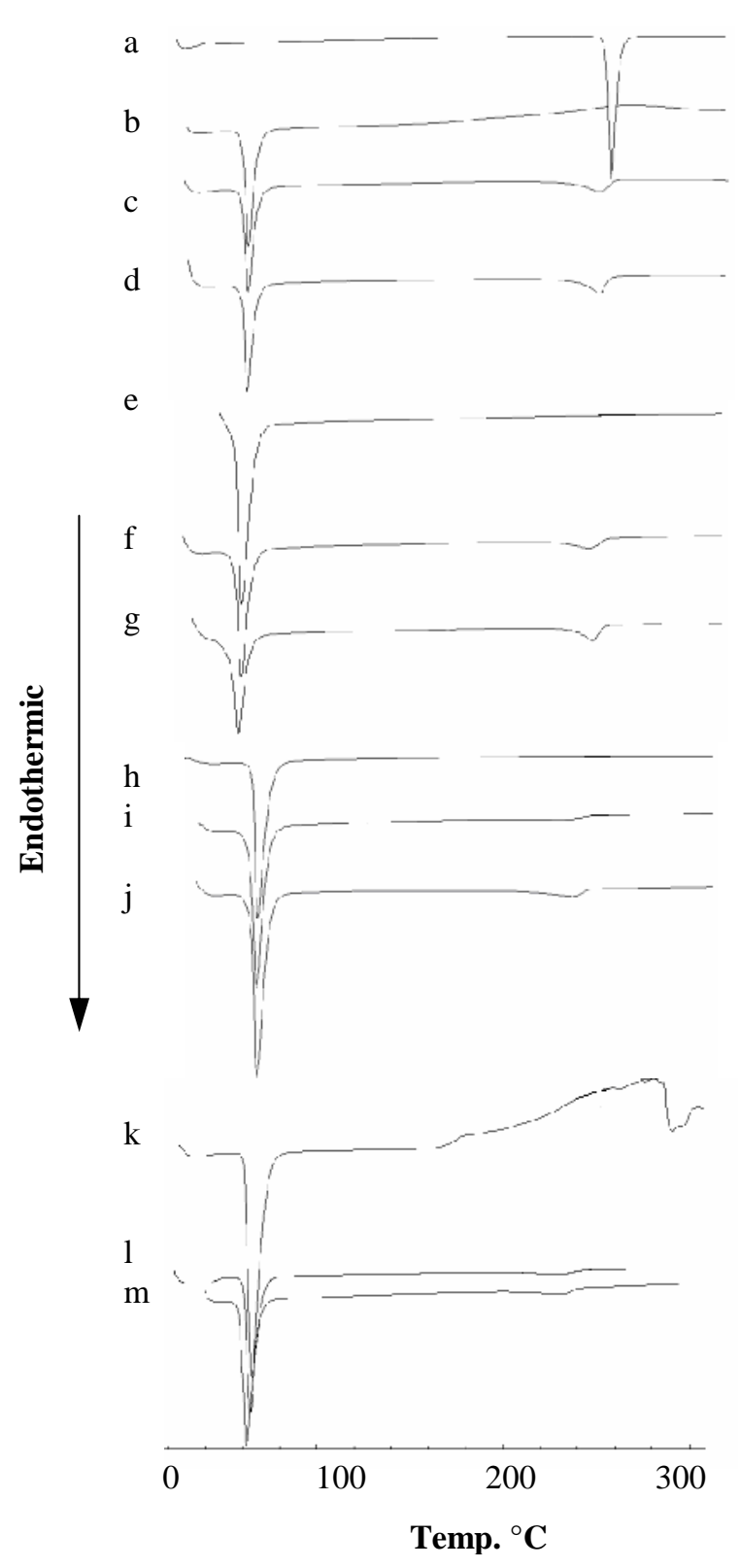

Fig. 6: DSC curves of single components and binary systems of domperidone and Pluronic F-127, Myrj 52, PEG 4000 and PEG 6000. (a) domperidone, (b) Pluronic F-127, (c) physical mixture of domperidone / Pluronic F-127, (d) melt granulation of domperidone / Pluronic F-127, (e) Myrj 52, (f) physical mixture of domperidone / Myrj 52, (g) melt granulation of domperidone / Myrj 52, (h) PEG 4000, (i) physical mixture of domperidone / PEG 4000, (j) melt granulation of domperidone / PEG 4000, (k) PEG 6000, (l) physical mixture of domperidone / PEG 6000, (m) melt granulation of domperidone / PEG 6000. 


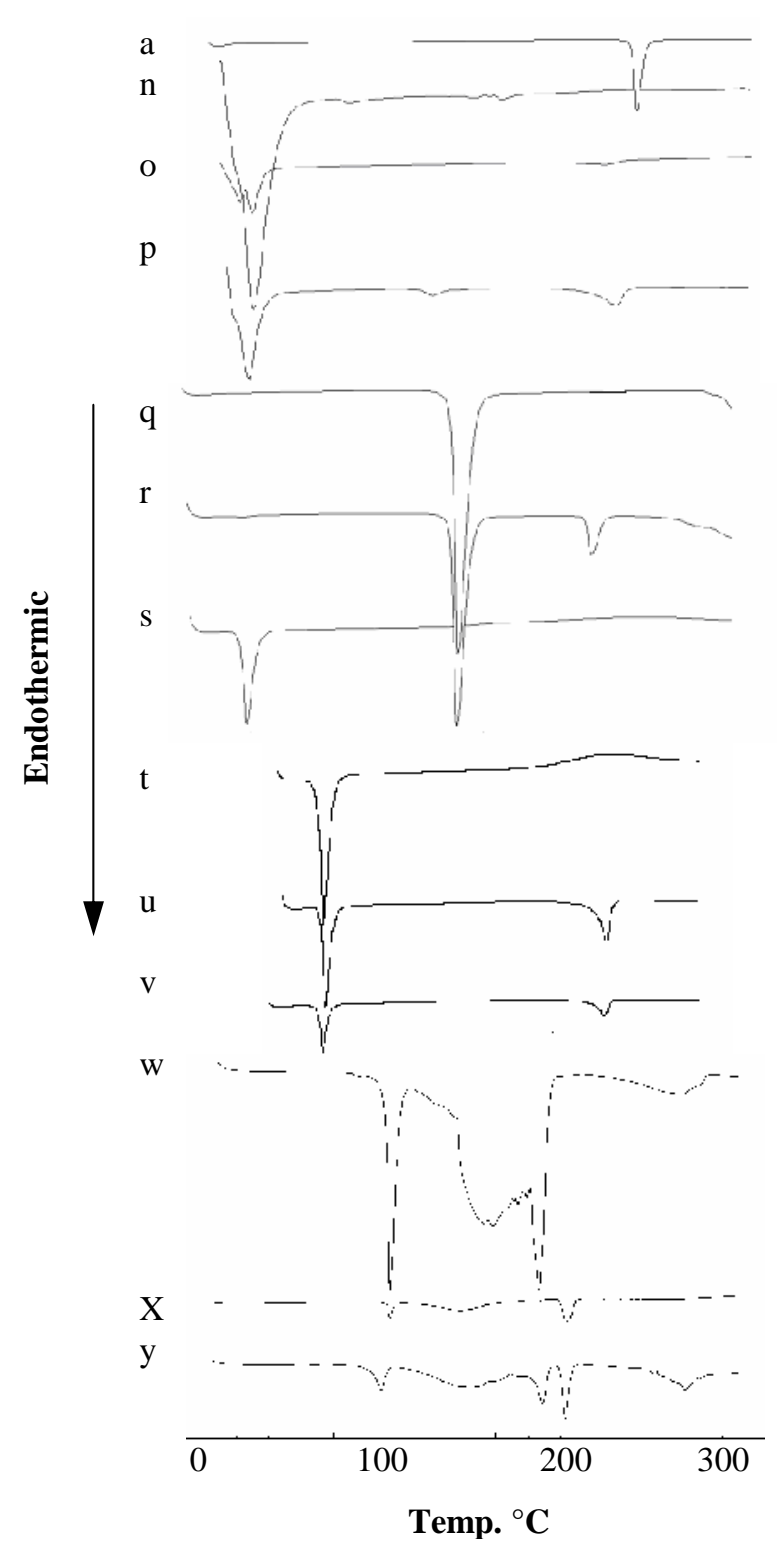

Fig. 7: DSC curves of single components and binary systems of domperidone and Brij 35, Mannitol, Pluronic F-68, and urea (a) domperidone, (n) Brij 35, (o) physical mixture of domperidone / Brij 35, (p) melt granulation of domperidone / Brij 35, (q) Mannitol, (r) physical mixture of domperidone / Mannitol, (s) melt granulation of domperidone / Mannitol, (t) Pluronic F68, (u) physical mixture of domperidone / Pluronic F-68, (v) melt granulation of domperidone / Pluronic F-68, (w) urea, (x) physical mixture of domperidone / urea, (y) melt granulation of domperidone / urea.

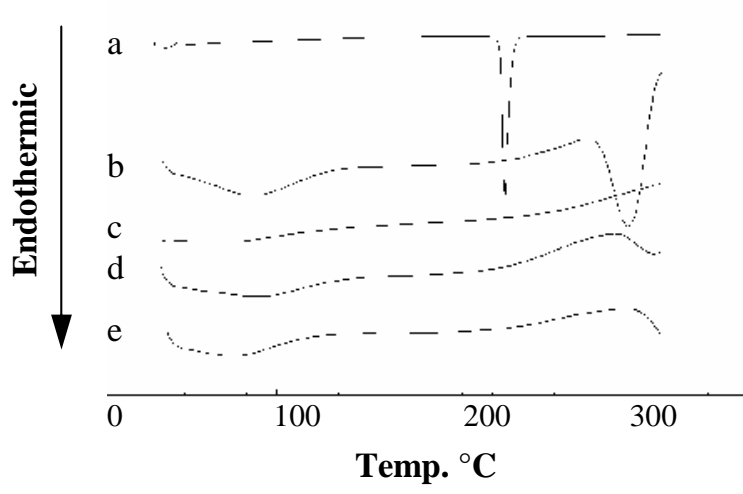

Fig. 8: DSC thermogram of domperidone liquisolid compacts systems. (a) domperidone alone, (b) Avicel, (c) Aerosil, (d) physical mixture, (e), liquisolid compacts (10\% tween 80$)$.

\section{Powder X-ray diffraction (XRD)}

The crystallinity of the drug, domperidone/Pluronic F-127 coevaporate and physical mixture at ratios of 1:3 was determined by PXRD (Philips model PW1050, USA) (Fig. 9). In the diffractograms, the pattern of drug alone, (trace a), shows the presence of numerous distinct diffraction peaks indicating that, the drug is present as a crystalline form. Diffractogram of PF-127 (trace b), shows two diffraction peaks at $23.2 \mathrm{~A}^{\circ}$ and $19.1 \mathrm{~A}^{\circ}$ with relative intensities of 100 and 71 respectively, indicating its crystalline nature. Diffractogram of the physical mixture, (trace c), possess the diffraction peaks of both the drug and the polymer, indicating that domperidone is in the crystalline state. The intensity of the drug peaks are attenuated due to lower drug content. Diffractogram of domperidone/PF-127 solid dispersion, (trace d), shows complete absence of the drug characteristic peaks. This indicates conversion of the drug from crystalline to amorphous state.

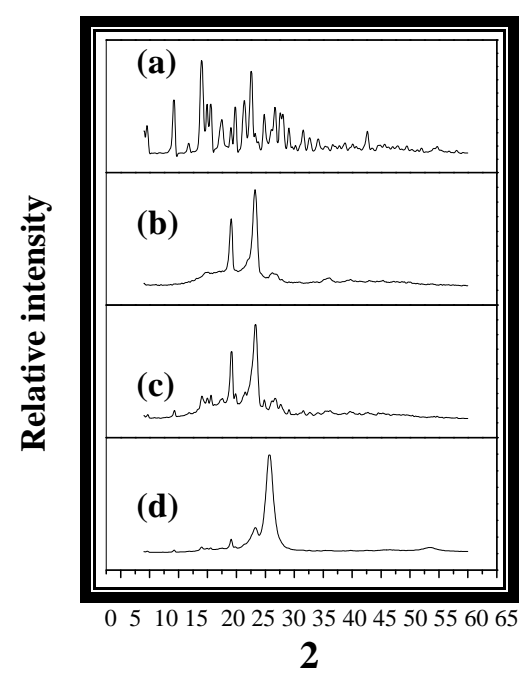

Fig. 9: Powder X-ray diffraction patterns of domperidone / Pluronic F-127 systems. (a) domperidone alone, (b) PF-127, (c) domperidone / Pluronic F-127 physical mixtures (1:3), (d) domperidone/Pluronic F-127 coevaporates (1:3). 


\section{Scanning electron microscopy (SEM)}

Photomicrographs of domperidone, PF127 and domperidone/ PF-127 solid dispersion as well as physical mixture are shown in figure 10 (a-d). The drug alone appears as crystals of hexagonal shape (Fig. 10a) which were relatively smaller than particles of PF-127 (Fig. $10 \mathrm{~b}$ ); the physical mixture of the drug and the carrier (Fig. 10c) shows the presence of drug in the crystalline form. Domperidone / PF-127 solid dispersion revealed absence of crystalline structure of the drug (Fig. 10d); it shows the topological changes produced in the carrier particles, the carrier surface seems to be more porous in nature, Thereby supporting the transformation of drug from the crystalline to the amorphous state.

Solid state characterization studies revealed partial loss of drug crystallinity which can bring about significant change(s) in the drug dissolution rate. However, other factors like reduced particle size, increased surface area, and closer contact between the hydrophilic carrier and the drug may also be influential in enhancing drug solubility and/or dissolution rate observed with the solid dispersion particles. (a)

(c)
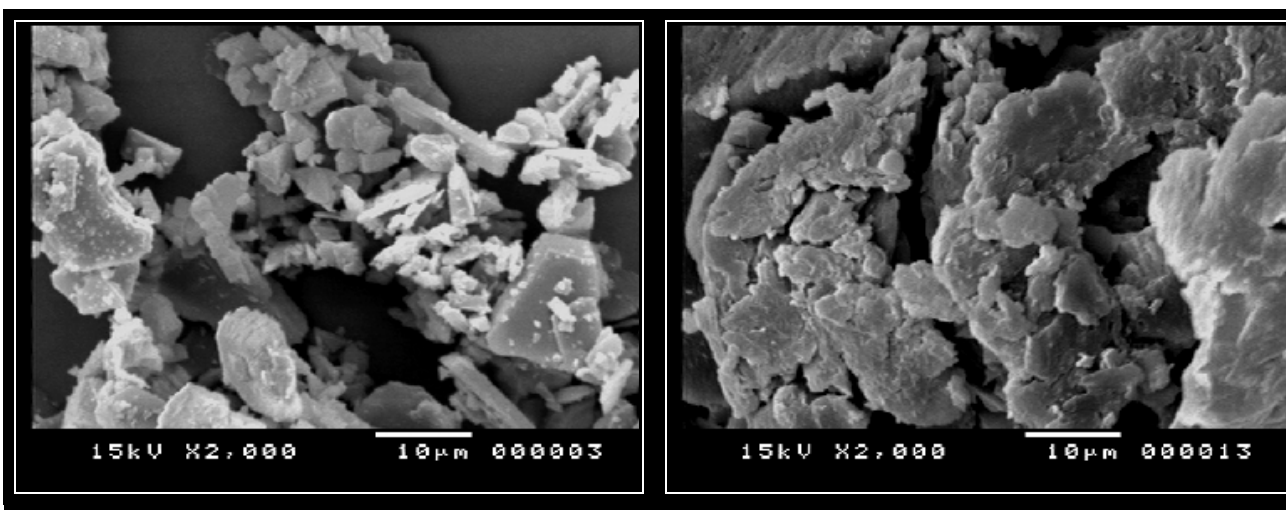

(b)

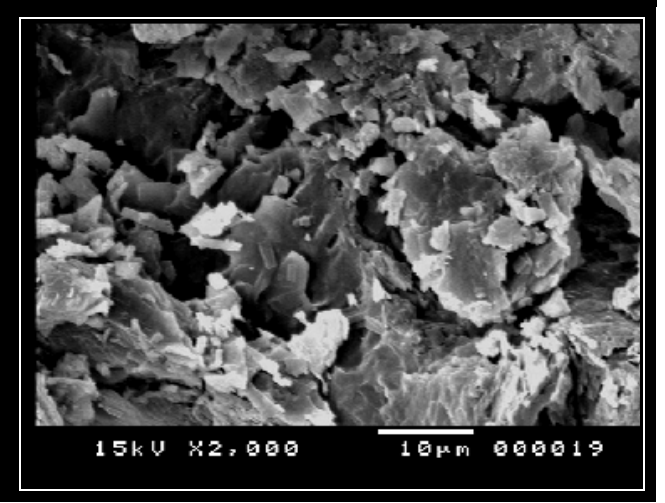

(d)

Fig. 10: Scanning electron micrographic image of domperidone/Pluronic F-127 systems. (a) domperidone alone, (b) PF-127, (c) domperidone/Pluronic F-127 physical mixtures (1:3), (d) domperidone/ Pluronic F-127 coevaporates $(1: 3)$. 


\section{Solubility determination}

Domperidone has a high melting point $\left(244^{\circ} \mathrm{C}\right.$ to $\left.248^{\circ} \mathrm{C}\right)$ which is indicative of strong crystal lattice energy. This is one of the factors responsible for poor aqueous solubility. Therefore, any approach which disrupts the crystalline nature would be more successful in improving aqueous solubility of domperidone.

Figure 11 displays the amount of domperidone solubilized from dispersion systems with different carriers at different drug: carrier ratios (1:1,1:2, and 1:3) prepared with solvent evaporation method. It is clear that, Myrj 52 exerts the highest solubilizing effect followed by PEG 4000, PVP, PF-127, and PEG 6000 compared to drug alone (solubility is $6.576 \mu \mathrm{g} / \mathrm{ml}$ ).

These results are in a good agreement with those obtained by Ahuja et al., and Van den Mooter et al. ${ }^{28 \& 29}$.

Figure 12 displays the amount of domperidone solubilized from melt granulation systems with different carriers at different drug: carrier ratios $(1: 1,1: 2$, and 1:3). It was noted that Myrj 52 exerts the highest solubilizing effect followed by Pluronic F-68, Brij 35, Pluronic F-127, PEG 4000, Mannitol, PEG 6000, and finally Urea.

This could be explained by, during elaboration of dispersions, the drug is partially dissolved in the melted carrier. After solidification, the drug will not nucleate, and hence, only microcrystals of drug are formed. Furthermore, the hydrophilic polymers cause rapid wetting of drug and decrease aggregation and agglomeration of drug particles leading to an improvement in its dissolution rate ${ }^{30}$.

Figure 13 displays the amount of domperidone solubilized from liquisolid compacts systems using different liquid vehicles with different drug concentrations. The figure shows that the drug concentration in the liquid medication is one of the main factors on the performance of that liquisolid compact and has considerable effect on the amount of domperidone solubilized. It can be seen that the amount of domperidone solubilized decreased with an increase in the concentration of drug or reduction in the concentration of liquid vehicle used. This is in accordance with results obtained by by javadzadeh et $a .^{21}$ for piroxicam liquisolid compacts. It was noted that Tween 80 and Tween 60 showed the highest solubilizing effect.

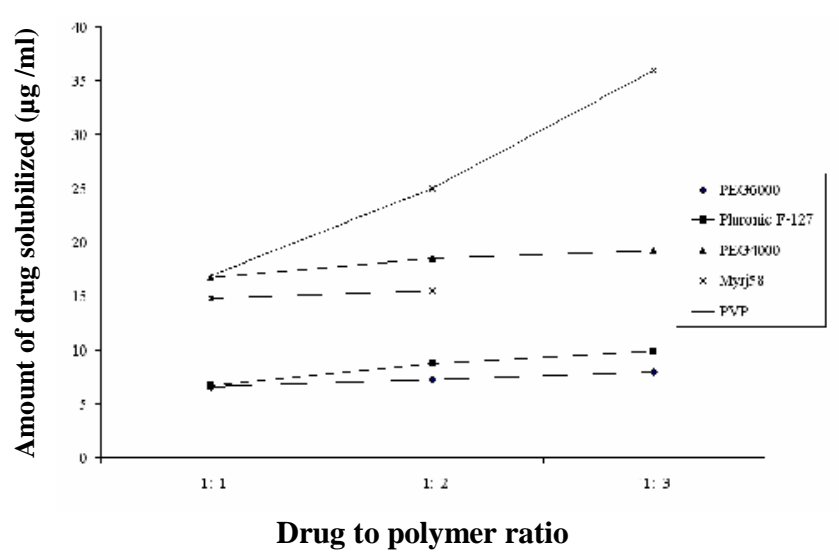

Fig. 11: Solubility of domperidone from its solid dispersion with different carriers at $(1: 1$, $1: 2$, and $1: 3$ ) in water at $37^{\circ} \mathrm{C}$.

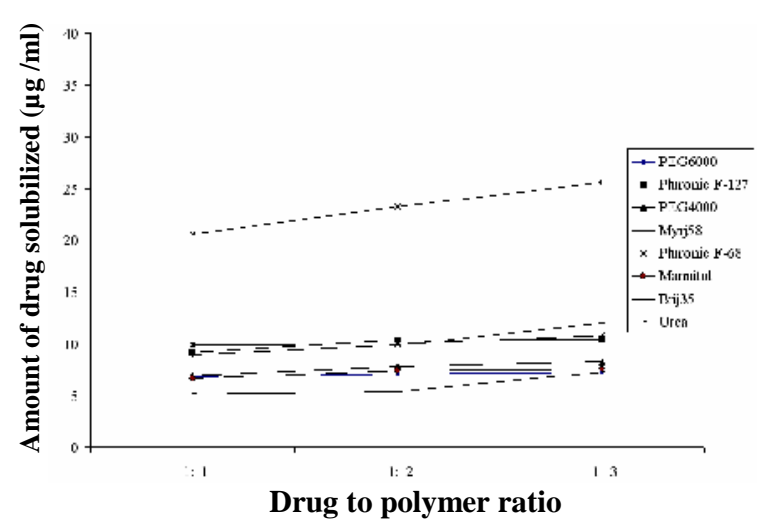

Fig. 12: Solubility of domperidone from its melt granulation with different carriers at $(1: 1$, $1: 2$ and $1: 3)$ drug to carrier ratio in water at $37^{\circ} \mathrm{C}$.

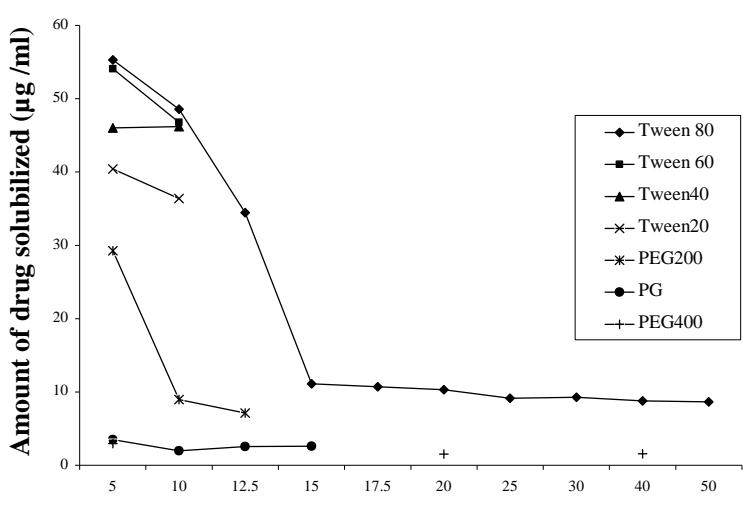

Drug concentration in liquid medication $(\% \mathrm{w} / \mathrm{w})$

Fig. 13: Solubility of domperidone from its liquisolid compacts with different carriers in water at $37^{\circ} \mathrm{C}$. 


\section{Dissolution studies}

Polymeric carriers which gave the highest solubilizing effect were chosen to study their effect on the dissolution rate of domperidone from domperidone / carrier solid dispersion system. The corresponding physical mixture in a ratio of drug: polymer that gave the highest solubilizing effect of domperidone was also studied.

Figure 14 displays the dissolution of domperidone from physical mixtures with the tested carriers. It was found that all physical mixtures exhibited higher dissolution rate than the drug alone, the highest dissolution obtained by Myrj 52, PF-127, followed by PEG 6000 and PEG 4000 in (1:3) drug: carrier ratio.

Figure 15 shows the dissolution rate of domperidone from solid dispersions in the ratio of (1:3) drug: polymer containing PF-127, PEG 6000 , Myrj 52 or of PEG 4000. They showed dissolution rate of $54.3,48.98,43.37$, and $43.2 \%$ of domperidone after 6 hrs respectively.

Comparing the dissolution rate of domperidone from the solid dispersions and the corresponding physical mixtures at ratio (1:3), it appears that solid dispersion of domperidone with PF-127, PEG 6000, Myrj 52, and PEG 4000 displayed faster and higher dissolution than the corresponding physical mixtures this may be due to in the physical mixtures only fair interactions exist between the drug and the carrier. Statistical analysis showed that there was a highly significant difference in the percent of drug dissolved from solid dispersion system and its corresponding physical mixture with Pluronic F-127 at (1:3) drug to carrier ratio $(\mathrm{P}<0.001)$ (Fig. 16).

The order of dissolution enhancement with various binary systems was found to be PF-127 > PEG $6000>$ Myrj 52 > PEG 4000. This order was not in exact consonance with that obtained during solubility study, where Myrj 52 showed higher solubility enhancement than PF-127.

This may be due to the formed coprecipitates lead to rapid supersaturation, an observation which has been reported by Simonelli et al. ${ }^{31}$ and Chiou \& Riegleman ${ }^{8}$.

Thus, it appears that coprecipitation alters the solid state of drug such that the dissolution enhancement is significantly higher than can be explained by the magnitude of the increase in solubility alone.
According to Fick's first law of diffusion, it can be concluded that the increase in viscosity reduces the dissolution rate of the drug. So Corrigan ${ }^{32}$ concluded that diffusion, rather than solubility considerations are likely to be dominant in determining the dissolution rate.

Statistical analysis revealed that there was highly significant difference in $\%$ of domperidone dissolved between solid dispersions of drug with Pluronic F-127, Myrj 52, PEG 6000, and PEG 4000 and that of the drug alone $(\mathrm{P}<0.001)$.

For melt granulation systems, Figures 1718 display the dissolution of domperidone from physical mixtures with the tested carriers. It was found that all physical mixtures exhibited higher dissolution than the drug alone except the physical mixture of the drug with urea in (1:1) drug to carrier ratio, the highest dissolution obtained by Myrj 52, PF-127, Brij 35, PF-68, mannitol followed by PEG 6000 and PEG 4000.

Figure 19 displays the dissolution of domperidone from melt granulation systems containing Myrj 52, PF-68, Brij 35, PF-127, mannitol, PEG 4000, PEG 6000 or urea. The amounts dissolved of domperidone after $6 \mathrm{hrs}$ were $23.76,16.17,13.88,13.78,10.94,8.59$, 5.37 , and $5.08 \%$ respectively. It is obvious that domperidone / Myrj 52 melt granulation (1:2) showed the highest dissolution of the drug and the melt granulation systems of the drug with either urea (1:1), or of PEG 6000 (1:3) showed dissolution rate lower than that of the drug alone. These results are in a good agreement with those obtained by El-Badry et al. ${ }^{33}$.

Statistical analysis showed that there was a highly significant difference in $\%$ of domperidone dissolved between melt granulation of drug with Pluronic F-127, Myrj 52, Pluronic F-68, mannitol, and Brij 35 and that of the drug alone $(\mathrm{P}<0.001)$. However there was a non significant difference between drug alone and melt granulations of drug with urea or PEG 6000.

Comparing the dissolution of domperidone from the solid dispersions prepared by the solvent evaporation method and those from melt granulation systems prepared by hot melt method, it appeared that the solid dispersions of domperidone displayed faster and higher dissolution than that prepared 
by melt granulation systems. This is in agreement with those obtained by Yzkan et al..$^{34}$.

Figure 20 displays the dissolution of domperidone from liquisolid compacts system containing $10 \%$ tween 80 , it showed an increase in dissolution of domperidone over that obtained for pure drug. Such enhanced drug dissolution rate may be mainly attributed to the fact that this poorly water soluble drug is already in solution in tween 80 , while at the same time, it is carried by the powder particles (microcrystalline cellulose-silica) of the liquisolid vehicle. Thus, its release is accelerated due to its markedly increased wettability and surface availability to the dissolution medium. These results are in agreement with those obtained by Javadzadeh et al. ${ }^{21}$.

It can be concluded that domperidone aqueous solubility and dissolution were markedly improved via solid dispersion technique with PF-127 prepared by solvent evaporation method compared to other techniques used (Fig. 21). This enhancement in the hydrophilic characters of the drug may be due to the change in its physicochemical properties. Statistical analysis revealed that there was a highly significant difference in percent of domperidone dissolved from solid dispersion, melt granulation, and liquisolid compacts systems compared to drug alone $(\mathrm{P}<$ 0.001 ), also the difference between solid dispersion system compared to the melt granulation and the liquisolid compacts systems was highly significant $(\mathrm{P}<0.001)$.

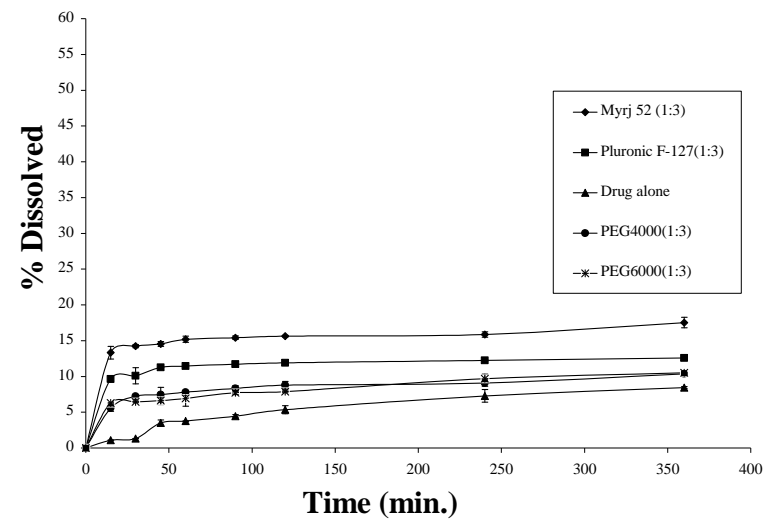

Fig. 14: Dissolution of domperidone from physical mixtures at (1:3) drug to carrier ratio in phosphate buffer $\mathrm{pH} 7.4$ at $37^{\circ} \mathrm{C}$.

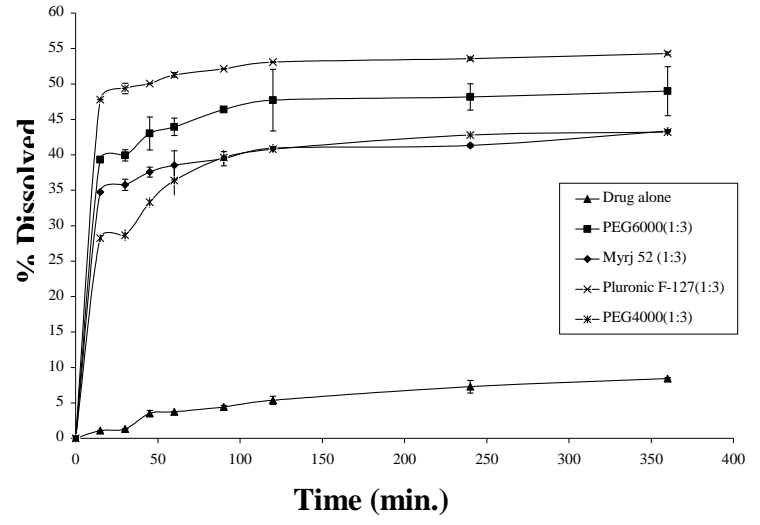

Fig. 15: Dissolution of domperidone from solid dispersion at (1:3) drug:carrier ratio in phosphate buffer $\mathrm{pH} 7.4$ at $37^{\circ} \mathrm{C}$.

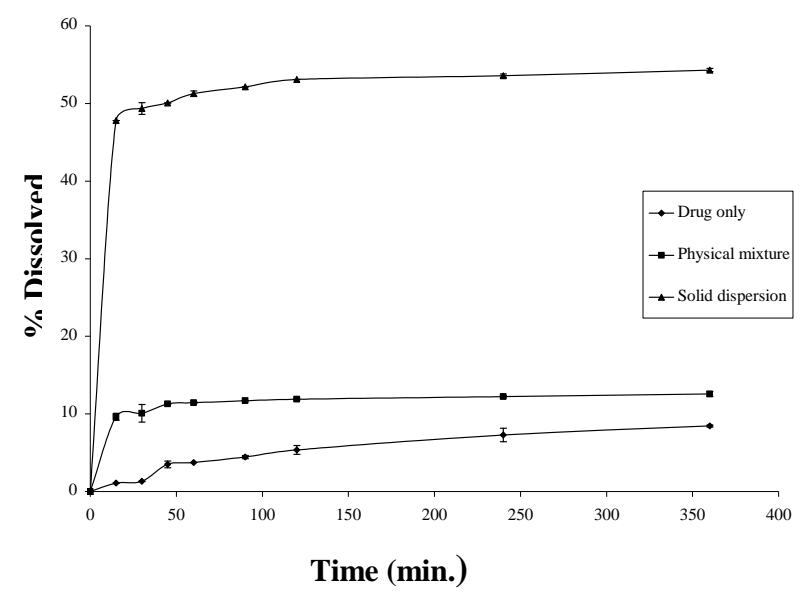

Fig. 16: Dissolution of domperidone from solid dispersion with Pluronic F-127, and its corresponding physical mixture in phosphate buffer $\mathrm{pH} 7.4$ at $37^{\circ} \mathrm{C}$.

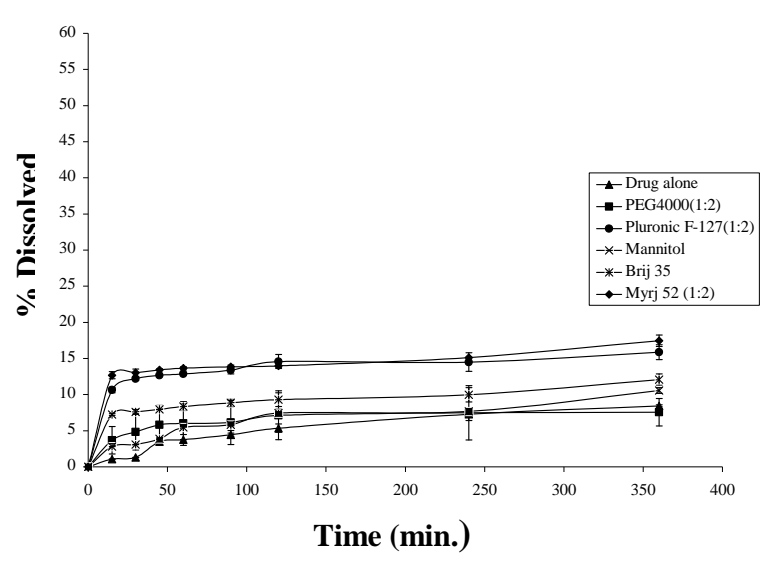

Fig. 17: Dissolution of domperidone from its physical mixtures at (1:2) drug:carrier ratio in phosphate buffer $\mathrm{pH} 7.4$ at $37^{\circ} \mathrm{C}$. 


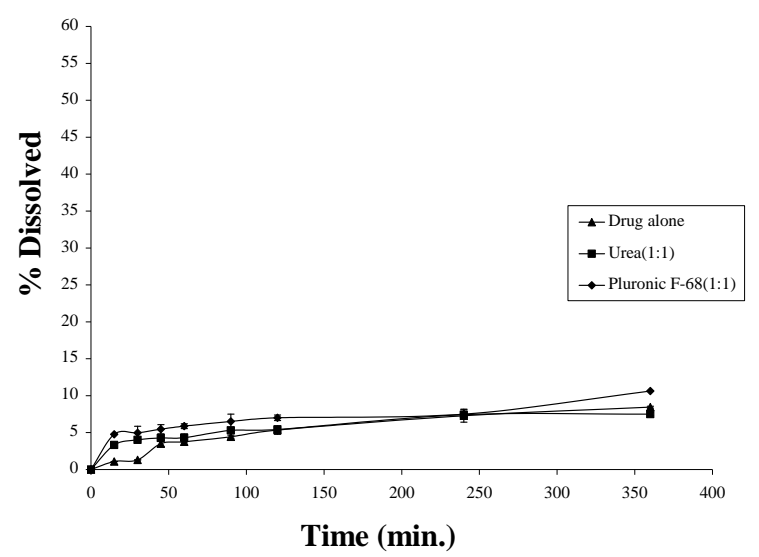

Fig. 18: Dissolution of domperidone from its physical mixtures at $(1: 1)$ drug carrier: ratio in phosphate buffer $\mathrm{pH} 7.4$ at $37^{\circ} \mathrm{C}$.

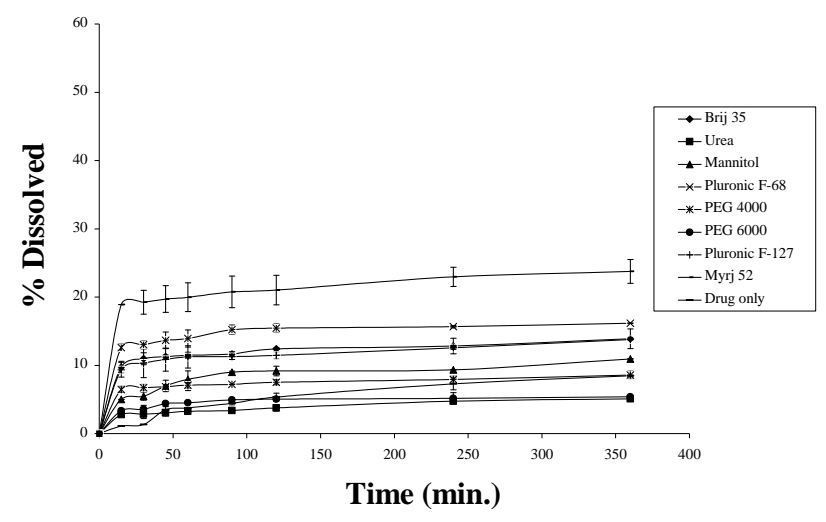

Fig. 19: Dissolution of domperidone from melt granulation in phosphate buffer $\mathrm{pH} 7.4$ at $37^{\circ} \mathrm{C}$.

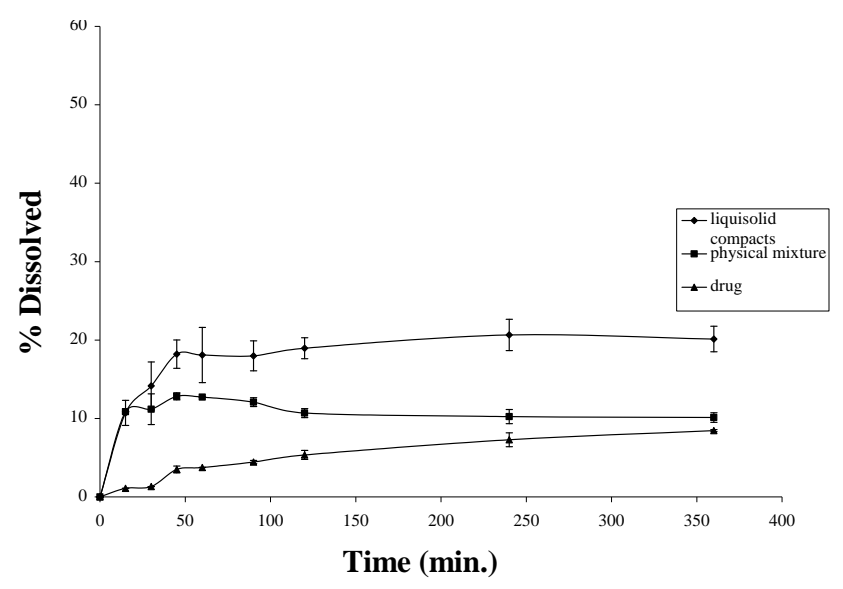

Fig. 20: Dissolution of domperidone from liquisolid compacts containing $10 \%$ tween 80 , and its corresponding physical mixture in phosphate buffer $\mathrm{pH} 7.4$ at $37^{\circ} \mathrm{C}$.

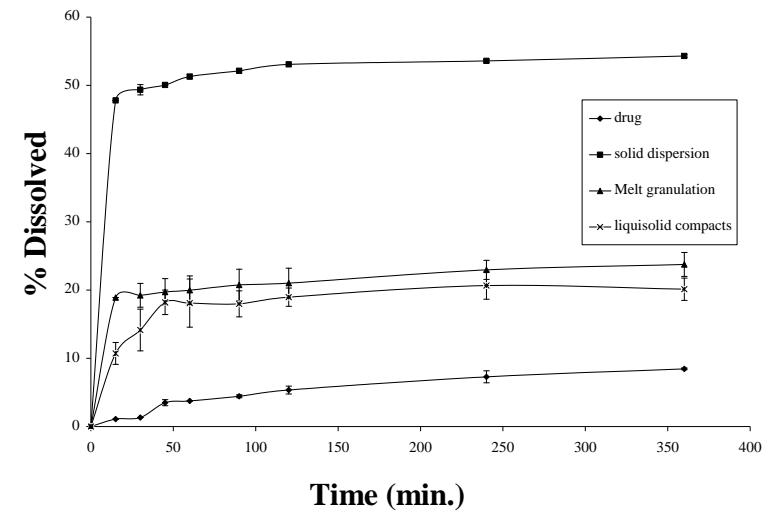

Fig. 21: Dissolution of domperidone from different prepared systems; solid dispersion, melt granulation, and liquisolid compacts in phosphate buffer $\mathrm{pH} 7.4$ at $37^{\circ} \mathrm{C}$.

\section{Conclusions}

Coevaporation of domperidone with Pluronic F-127 (1:3) drug to carrier ratio exhibited an increase in the percent of drug dissolved much higher than could be attained by melt granulation systems or liquisolid compact systems. Many factors contributed to faster release rate such as decrease in particle size, decrease in agglomeration of particles, increase wettability and decrease in crystallinity of the drug as demonstrated by $\mathrm{XRD}$, SEM, DSC and IR.The proposed amorphous solid dispersion ensures good pharmaceutical availability of domperidone.

\section{REFERENCES}

1- C. Dollery, "Therapeutic Drugs", $2^{\text {nd }}$ Edn., Vol. 1, A. Boobis, M. Rawlins, S. Thomas and M. Wilkins (eds.), Churchill Livingston, UK, 1999, pp. D196-D198.

2- S. C. Sweetman, "Martindale: The Complete Drug Reference", $33^{\text {rd }}$ Edn., Pharmaceutical Press, London, 2002, p. 1224.

3- C. Savio, M. D. Reddymasu, M. D. Irfan Soykan, W. Richard and M. D. Mccallum, "Domperidone: Review of pharmacology and clinical applications in gastroenterology", Am. J. Gastroenterol., 20362045 (2007).

4- R. W. Mccallum, "Review of the current status of prokinetic agents in gastroenterology", ibid., 80 (12), 1008-1016 (1985). 
5- J. Kerc, M. Mohar, B. Srcic and K. J. Smid, "Dissolution study of felodipine solid dispersions", Acta Pharm., 43, 113120 (1993).

6- H. Popli, R. S. Murthy and B. D. Miglani, "Solid dispersions as a drug delivery system for sulfamethoxazole and nitrofurantoin", Ind. J. Hosp. Pharm., 31, 97-100 (1994).

7- C. Goddeeris and G. Van den Mooter, "Free flowing solid dispersions of the antiHIV drug UC 781 with Poloxamer 407 and a maximum amount of TPGS 1000: Investigating the relationship between physicochemical characteristics and dissolution behaviour", Eur. J. Pharm. Sci., 35 (1-2), 104-113 (2008).

8- W. L. Chiou and S. Riegelman, "Pharmaceutical applications of solid dispersion systems", J. Pharm. Sci., 60 (9), 1281-1302 (1971).

9- K. Sekiguchi and N. Obi, "Studies on absorption of eutectic mixture. I. A comparison of the behavior of eutectic mixture of sulfathiazole and that of ordinary sulfathiazole in man", Chem. Pharm. Bull., 9 (11), 866-872 (1961).

10- J. L. Ford, "The current status of solid dispersions", Pharm. Acta Helv., 61 (3), 69-88 (1986).

11- T. Ozeki, H. Yuasa and Y. Kanaya, "Application of the solid dispersion method to the controlled release of medicine. IX. Difference in the release of flurbiprofen from solid dispersions with poly (ethylene oxide) and hydroxypropylcellulose and the interaction between medicine and polymers", Int. J. Pharm., 155 (2), 209-217 (1997).

12- B. C. Hancock and G. Zografi, "Characteristics and significance of the amorphous state in pharmaceutical systems", J. Pharm. Sci., 86 (1), 1-12 (1997).

13- P. C. Sheen, V. K. Khetarpal, C. M. Cariola and C. E. Rowlings, "Formulation studies of a poorly water-soluble drug in solid dispersions to improve bioavailability", Int. J. Pharm., 118 (2), 221227 (1995).

14- S. Janssens, H. N. de Armas, W. D'Autry, A. Van Schepdael and G. Van den Mooter, "Characterization of ternary solid dispersions of Itraconazole in polyethylene glycol 6000 / polyvidonevinylacetate 64 blends", Eur. J. Pharm. Biopharm., 69 (3), 1114-1120 (2008).

15- D. Q. M. Craig, "The mechanisms of drug release from solid dispersions in watersoluble polymers", Int. J. Pharm., 231 (2), 131-144 (2002).

16- D. Yang, R. Kulkarni, R. J. Behme and P. N. Kotiyan, "Effect of the melt granulation technique on the dissolution characteristics of griseofulvin", ibid., 329, 72-80 (2007).

17- B. Perissutti, F. Rubessa, M. Moneghini and D. Voinovich, "Formulation design of carbamazepine fast-release tablets prepared by melt granulation technique", ibid., 256 (1-2), 53-63 (2003).

18- L. Ochoa, M. Igartua, R. M. Hernlndez, A. R. Gasc $n$ and J. L. Pedraz, "Preparation of sustained release hydrophilic matrices by melt granulation in a high-shear mixer", J. Pharmacy Pharm. Sci., 8 (2), 132-140 (2005).

19- L. Rodriguez, C. Cavallari, N. Passerini, B. Albertini, M. L. Gonzllez-Rodriguez and A. Fini, "Preparation and characterization by morphological analysis of diclofenac / PEG 4000 granules obtained using three different techniques", Int. J. Pharm., 242 (1-2), 285-289 (2002).

20- S. Spireas and S. Sadu, "Enhancement of prednisolone dissolution properties using liquisolid compacts", ibid., 166 (2), 177188 (1998).

21- Y. Javadzadeh, M. R. Siahi-Shadbad, M. Barzegar-Jalali and A. Nokhodchi, "Enhancement of dissolution rate of piroxicam using liquisolid compacts", Il Farmaco, 60 (4), 361-365 (2005).

22- N. Tiong and A. A. Elkordy, "Effects of liquisolid formulations on dissolution of naproxen", Eur. J. Pharm. Biopharm., 73 (3), 373-384 (2009).

23- Y. Javadzadeh, B. Jafari-Navimipour and A. Nokhodchi, "Liquisolid technique for dissolution rate enhancement of a high dose water-insoluble drug (carbamazepine)", Int. J. Pharm., 341 (1-2), 26-34 (2007).

24- S. Lakshmana Prabu, A. Shirwaikar, A. Shirwaikar, C. Dinesh Kumar, A. Joseph and R. Kumar, "Simultaneous estimation 
of esomeprazole and domperidone by UV spectrophotometric method", Indian J. Pharm. Sci., 70 (1), 128-131 (2008).

25- A. Burger, J.O. Henck, S. Hetz, J. M. Rollinger, A. A. Weissnicht and $\mathrm{H}$. St ttner, "Energy/temperature diagram and compression behavior of the polymorphs of D-mannitol", J. Pharm. Sci., 89 (4), 457-468 (2000).

26- J. A. Mccauley and H. G. Brittain, "Physical Characterization of Pharmaceutical Solids, Drugs and Pharmaceutical Sciences", H. G. Brittain, (Editor), Marcel Dekker Inc., New York, 1995, pp. 223250.

27- P. Mura, M. T. Faucci and P. L. Parrini, "Effects of grinding with microcrystalline cellulose and cyclodextrins on the ketoprofen physicochemical properties", Drug Dev. Ind. Pharm., 27 (2), 119-128 (2001).

28- N. Ahuja, O. P. Katare and B. Singh, "Studies on dissolution enhancement and mathematical modeling of drug release of a poorly water-soluble drug using watersoluble carriers", Eur. J. Pharm. Biopharm., 65 (1), 26-38 (2007).

29- G. Van den Mooter, P. Augustijns, N. Blaton and R. Kinget, "Physico-chemical characterization of solid dispersions of temazepam with polyethylene glycol 6000 and PVP K30", Int. J. Pharm., 164 (1-2), 67-80 (1998).
30- M. J. Arias, J.M. Gin, J. R. Moyano and A.M. Rabasco, "Dissolution properties and in-vivo behaviour of triamterene in solid dispersions with polyethylene glycols", Pharm. Acta Helv., 71, 229-235 (1996).

31- A. P. Simonelli, S. C. Mehta and W. I. Higuchi, "Dissolution rates of high energy polyvinylpyrrolidone (PVP) sulfathiazole coprecipitates", J. Pharm. Sci., 58 (5), 538-549 (1969).

32- O. I. Corrigan, "Mechanisms of dissolution of fast release solid dispersions", Drug Dev. Ind. Pharm., 11 (2-3), 697-724 (1985).

33- M. El-Badry, G. Fetih and M. Fathy, "Improvement of solubility and dissolution rate of indomethacin by solid dispersions in Gelucire 50/13 and PEG 4000", Saudi. Pharm. J., 17 (3), 217-225 (2009).

34- Y. I. Yzkan, N. Doanay, N. Dikmen and A. I. Iimer, "Enhanced release of solid dispersions of etodolac in polyethylene glycol", Il Farmaco, 55 (6-7), 433-438 (2000). 